5-18-2019

\title{
Multiple drivers of interannual oyster settlement and recruitment in the lower Chesapeake Bay
}

\author{
Brendan Turley \\ Virginia Institute of Marine Science \\ Kimberly S. Reece \\ Virginia Institute of Marine Science \\ Jian Shen \\ Virginia Institute of Marine Science \\ Jeong-Ho Lee \\ Ximing Guo
}

See next page for additional authors

Follow this and additional works at: https://scholarworks.wm.edu/vimsarticles

Part of the Aquaculture and Fisheries Commons

\section{Recommended Citation}

Turley, Brendan; Reece, Kimberly S.; Shen, Jian; Lee, Jeong-Ho; Guo, Ximing; and McDowell, Jan, "Multiple drivers of interannual oyster settlement and recruitment in the lower Chesapeake Bay" (2019). VIMS Articles. 1459.

https://scholarworks.wm.edu/vimsarticles/1459

This Article is brought to you for free and open access by the Virginia Institute of Marine Science at W\&M ScholarWorks. It has been accepted for inclusion in VIMS Articles by an authorized administrator of W\&M ScholarWorks. For more information, please contact scholarworks@wm.edu. 


\section{Authors}

Brendan Turley, Kimberly S. Reece, Jian Shen, Jeong-Ho Lee, Ximing Guo, and Jan McDowell 
1 TITLE: Multiple drivers of interannual oyster settlement and recruitment in the lower Chesapeake Bay

3 AUTHORS: Brendan Turley ${ }^{1,2}$, Kimberly Reece ${ }^{1}$, Jian Shen ${ }^{1}$, Jeong-Ho Lee ${ }^{3}$

4 Ximing Guo ${ }^{3}$, Jan McDowell ${ }^{1 *}$

6 AUTHOR AFFILIATIONS:

7 1. Virginia Institute of Marine Science, College of William and Mary, Gloucester Point, VA, USA, 23062

8 2. Current address: School of the Earth, Ocean and Environment, University of South Carolina, Columbia, 9 SC, USA, 29208

10 3. Haskin Shellfish Research Laboratory, Rutgers University, Port Norris, NJ, USA, 08349

$11 *$ Corresponding author email: mcdowell@vims.edu, +1-804-684-7263

\section{AKNOWLEDGEMENTS:}

14 We would like to acknowledge Virginia Sea Grant for providing program development funds and Tidewater Oyster

15 Growers Association for granting B. Turley a fellowship in support for this research. We would also like to thank

16 the Chesapeake Bay Foundation (CBF) especially, Tommy Leggett, Jackie Shannon, CBF volunteers, and citizen

17 scientist volunteers living on the Lafayette River that took care of spat collectors and provided dock space for this

18 research. Also, Jane Dodge and students in her marine science class from Grafton High School in Yorktown,

19 Virginia were instrumental in counting oyster spat. Thanks to Heidi Brightman for laboratory support at the Virginia

20 Institute of Marine Science (VIMS), and Fluidigm technical support. Thank you to B. Turley's committee members

21 Dr. Roger Mann and Dr. Mike Newman for their helpful suggestions. Thanks to Dr. Melissa Southworth and crew

22 of Virginia Marine Resources Commission vessel J. B. Baylor for their assistance in getting wild oyster samples.

23 And thanks to Dr. Ryan Carnegie at VIMS for providing Rappahannock River oyster samples. This work constitutes

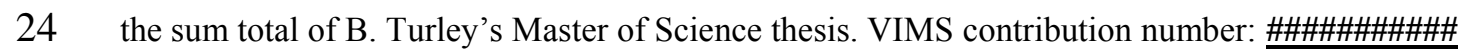




\section{Turley et al. Interannual oyster recruitment}

25 ABSTRACT: Despite global investment in shellfish restoration activities, relatively little attention has been given to

26 predicting optimal restoration sites and testing these expectations. We used a coupled biological-physical

27 connectivity model as a guide to plant two distinct hatchery-spawned strains of the eastern oyster, Crassostrea

28 virginica, in the Lafayette River, Virginia during the summer of 2013 at two locations corresponding to virtual

29 spawning locations within the connectivity model. We utilized single nucleotide polymorphism markers to test the

30 model predictions by genotyping oyster recruitment the year after planting and examining interannual recruitment

31 variability for two successive years. None of our experimental oyster genotypes were detected; however, we did

32 observe a genetic influence from an oyster strain used previously for restoration. Differences in environmental

33 conditions between the two years of monitored recruitment likely affected larval dispersal and survival contributing

34 to observed interannual differences in the demographics of newly recruiting cohorts. Oyster recruits from 2013 were

35 genetically more similar to resident adults sampled in the Lafayette River, while the 2014 recruits exhibited

36 genotypic frequencies more similar to adults from surrounding rivers. The winds during the spawning seasons

37 differed between years providing conditions for retention in 2013 and mixing of water masses in 2014. We

38 recommend that the monitoring of restoration activities should consider relevant environmental conditions and

39 observe multiple years of recruitment to assess the genetic impacts of restoration plantings and variable reproductive

40 success.

41

42 KEY WORDS: citizen science; connectivity; Crassostrea virginica; restoration; seascape genetics; single nucleotide 43 polymorphism 
Turley et al. Interannual oyster recruitment

\section{INTRODUCTION}

Traditionally, population genetic studies of larval and juvenile dispersal have focused primarily on the correlation between genetic and geographic distances to understand population connectivity. More recently, contemporary landscape genetics methods used in terrestrial environments have considered environmental data in addition to geographic distances to explain regional population structure; however, the marine environment presents unique challenges (Selkoe et al. 2016). For example, ocean surface currents forced by winds and tidal cycles are two important factors impacting the distribution and survival of estuarine organisms. As a result, the physical dynamics of estuaries are vital to understanding resident organisms, and hydrodynamic models that incorporate biological components are valuable for formulating population connectivity hypotheses. Restoration projects located in estuaries could benefit from the combination of physical modeling and population genetic analyses to better predict optimal restoration sites and track the reproductive influence of restoration introduced animals.

Molecular markers have been used for tracking the efficacy of restoration projects by monitoring the genetic contribution of planted animals to newly recruiting individuals with varying success. In 2002, the Virginia Marine Resources Commission (VMRC) working with Virginia Institute of Marine Science (VIMS) researchers planted a selectively bred strain of oyster in the Great Wicomico River, Virginia with the goal of using nuclear microsatellite markers to track the progress of restoration efforts (Hare et al. 2006, Carlsson et al. 2008). Hare et al. (2006) identified a single oyster spat (of 1579) as a full offspring of the restoration planted oysters and 153 (9.7\%) as F1 hybrids. Milbury et al. (2004) successfully used mitochondrial 16S ribosomal DNA sequences to detect genotypes specific to oysters planted for restoration in Delaware Bay. Although the percentage of recovered spat, spat defined as post-larval oysters less than 6 months old, assigned to oysters introduced during restoration efforts was low $(\sim 0.08 \%)$, the results confirmed that introduced oysters were contributing to reproductive output. Wilbur et al. (2005) determined that a small percentage of bay scallop (Argopecten irradians) recruits ( 0.03\%) were genetically related to restoration planted animals on the west coast of Florida based on two randomly amplified mitochondrial DNA (mtDNA) fragments. While these previous tracking studies had lower returns than expected $a$ priori, they did demonstrate the utility of molecular markers for monitoring the reproductive contribution of restoration planted organisms.

The eastern oyster, Crassostrea virginica, has a continuous distribution along the eastern coast of North America ranging from the Yucatan Peninsula in the south to Nova Scotia in the north (Buroker 1983). The 
Turley et al. Interannual oyster recruitment

72 Chesapeake Bay is an important habitat for $C$. virginica and this region has a history of fishery exploitation

73 contributing to population declines of oysters and reduction in the number of oyster reefs (Jackson et al. 2001). The

74 ecosystem value of oysters has been estimated to range from $\$ 5,500$ to $\$ 99,000$ per hectare per year (Grabowski et

75 al. 2012), and government agencies and non-governmental organizations have invested significant resources in

76 oyster restoration within the Chesapeake Bay (USACE 2012). Restoration projects that plant live animals into the

77 ecosystem assume that the restoration oysters will supplement the wild populations and contribute to future

78 reproduction. Despite the emphasis on restoring oyster reefs in the Chesapeake Bay, there has been relatively little

79 attention given to assessing the direct reproductive contribution of oysters planted during restoration activities.

80 Our study was a collaboration that has its origins in C. virginica restoration efforts managed by the

81 Chesapeake Bay Foundation (CBF). Since 1999, CBF has constructed oyster reefs in the Lafayette River, Virginia

82 and planted oysters on many of these artificial reefs. To maximize the impact of the restoration efforts, the CBF

83 contracted a modeling group at VIMS to develop a biological-physical connectivity model (referred to as

84 connectivity model), which included oyster larvae behavior, to predict locations that would have the greatest larval

85 export potential and locations that would have the greatest larval settlement in the Lafayette River (Sisson and Shen

86 2012). The CBF used the predictions of the connectivity model as a guide to plant two hatchery-spawned strains in

87 the Lafayette River during the summer of 2013 at two locations corresponding to virtual spawning locations within

88 the model. We developed a panel of single nucleotide polymorphism (SNP) markers and used them to determine

89 whether there was evidence that genetically characterized, planted oysters were reproducing and contributing to

90 annual recruitment within the Lafayette River. Moreover, we compared the settlement and recruitment of oysters

91 between two successive years in the Lafayette to better understand differences on interannual timescales. We also

92 examined two years of oyster settlement data in the Lafayette River to make a qualitative comparison to the

93 predictions produced by the biological-physical model created by Sisson and Shen (2012).

METHODS

\section{EXPERIMENTAL OYSTER PLANTINGS}

96 CBF introduced two hatchery-spawned oyster strains into the Lafayette River during the summer of 2013 to

97 experimentally track restoration-associated recruitment within the Lafayette. Adult oysters $\left(\mathrm{n}_{\text {females }}=35, \mathrm{n}_{\text {males }}=12\right)$

98 were collected from Cod Harbor, Tangier Island, Virginia (Figure 1a) by VMRC and strip-spawned at Oyster Seed

99 Holdings, LLC, Goodwin Island, Virginia in July 2013. About 1.8 million hatchery-spawned Tangier Island oysters 
Turley et al. Interannual oyster recruitment

100 were deployed as spat attached to cleaned oyster shell at the Granby Street Bridge reef (Figure 1b) in August 2013.

101 Oysters from Tangier were used for this study because Tangier Island is geographically distant from the Lafayette

102 River (>100 km), the prominent larval dispersal patterns do not favor direct connectivity between the two systems

103 (North et al. 2008), and previous research found a pattern of isolation by distance for Crassostrea virginica in the

104 Chesapeake Bay (Rose et al. 2006). These lines of evidence suggested that oysters from Tangier and the Lafayette

105 would be genetically distinct from each other. Additionally, about 114,000 Northeast High-Survival line (NEH ${ }^{\circledR}$ )

106 cultchless oysters, which are individual oysters not attached to substrate, were deployed at the Larchmont reef

107 (Figure 1b) in August 2013. The $\mathrm{NEH}^{\circledR}$ oysters were spawned at Rutgers Haskin Shellfish Hatchery in Port Norris,

108 New Jersey during November 2012 and were donated by CBF from a decommissioned oyster lease located at

109 Sarah's Creek, Virginia. The $\mathrm{NEH}^{\circledR}$ oysters were used because they are a selectively-bred strain that are

110 reproductively capable and was known to be sufficiently different from wild oysters in the lower Chesapeake Bay

111 (defined here as the James, Elizabeth and Lafayette Rivers) to be used for recruitment tracking using genetic

112 methods. The experimental oysters were planted on separate reefs chosen to coincide with virtual oyster larvae

113 release locations within the Sisson and Shen (2012) connectivity model. The experimental planting locations were

114 selected as a trade-off between model predictions, existing restoration reef locations, and locations with reasonable

115 survival probability due to habitat characteristics. The Granby reef was predicted to have the second highest larval

116 production potential after a location upriver (Sisson and Shen 2012). The upriver location with highest larval

117 production potential is muddy and subject to environmental extremes not suitable for larval survival. The Larchmont

118 reef was already the site of an extensive artificial reef with high densities of healthy oysters.

119 OYSTER SAMPLING

Adult oysters were sampled from multiple locations in the Chesapeake Bay to serve as reference groups to

121 compare against spat sampled in the Lafayette River (Figure 1a). Oysters were acquired from the Elizabeth, James,

122 and Great Wicomico Rivers by the VMRC vessel J. B. Baylor with hydraulic patent tong (methods detailed by

123 Southworth and Mann 2015). Sampling was conducted during annual oyster surveys in the autumns of 2013 and

1242014 from randomly selected locations in the three rivers; however, the Great Wicomico was only sampled in 2014

125 by dredge. Rappahannock River samples were obtained during the summer of 2015 from an annual naïve oyster

126 disease survey conducted by researchers at VIMS. In the Elizabeth River, Hospital Point and the Western Branch

127 reefs were sampled. Cruiser's Rock, Wreck Shoals, and Upper Deep-Water Shoal reefs were sampled in the James 
Turley et al. Interannual oyster recruitment

128 River. Colley Avenue Bridge, the seawall on Mayflower Road, and Granby Street Bridge were sampled in the

129 Lafayette River. In addition, subsamples of the $\mathrm{NEH}^{\circledR}$ oysters and Tangier Island offspring, which were planted in

130 the Lafayette River as our experimental oysters, were collected for genotyping. For this paper, samples refer to

131 groups of individuals collected in the same river system as reference and groups of individual spat obtained from

132 spat-collectors in same year. Sample abbreviations are as follows: Lafayette River adult reference (LR), Lafayette

133 River 2013 spat (LR13), Lafayette River 2014 spat (LR14), Elizabeth River reference (ER), James River reference

134 (JR), Rappahannock River reference (RR), Great Wicomico River reference (GR), Tangier Island offspring (TI), and

135 Northeast High-Survival Line $\left(\mathrm{NEH}^{\circledR}\right)$.

136 The CBF's citizen-science spat-collector program was used to quantify the magnitude of oyster recruitment

137 into the Lafayette River and to obtain spat samples for genotyping. The spat collectors were placed on the docks of

138 volunteers within the Lafayette River from May through October of 2013 and 2014. Collectors were positioned

139 approximately 15 centimeters off the bottom and agitated weekly to remove sediment. Spat from retrieved spat-

140 collectors were returned to the lab, and proportionate sampling was used to obtain a representative sample of the

141 spat distribution from the river.

142 Shell-string surveys were used to quantify larval supply and settlement timing within the Lafayette River.

143 This survey was designed to capture late-stage larvae recently attached to substrate. The surveys were conducted at

144 the docks of four volunteers in the Lafayette River from May through October in 2013 and 2014. One location was

145 upriver, two were mid-river, and one was near the mouth of the river (Figure 1b). Shell-strings consisted of ten

146 cleaned oyster shells with a hole drilled in the center and hung on 12.5-gauge wire. The shell-strings were suspended

147 from docks about $15 \mathrm{~cm}$ off the bottom. Every other week the old shells were removed for sampling and replaced

148 with new shells. A dissection microscope was used to enumerate larvae that settled on the oyster shells.

149 OYSTER GENOTYPING

150 Gill, mantle, and adductor-muscle tissue were sampled via sterile technique for DNA extraction and were

151 preserved in 95\% ethanol. Genomic DNA was isolated from tissue samples using either the DNeasy Blood and

152 Tissue Kit (Qiagen, Valencia, CA) or the Genomic DNA - Tissue MicroPrep Kit (Zymo Research, Irvine, CA)

153 using the manufacturers' protocols. Concentration and purity of extracted DNA was quantified on either a

154 NanoDrop 2000 or Qubit spectrophotometer (Thermo Fisher Scientific, Waltham, MA) and only samples with

155 concentrations greater than $5.0 \mathrm{ng} / \mu \mathrm{l}$ were used for genotyping. 
Turley et al. Interannual oyster recruitment

The SNP markers used in this study were designed based on published (Zhang and Guo 2010) and

unpublished loci originally developed from expressed sequence tags to assess disease resistance in hatchery-selected

158 strains of $C$. virginica. A total of 95 loci were converted to SNPtype assays (Fluidigm, San Francisco, CA) using

159 the D3 ${ }^{\mathrm{TM}}$ Assay Design software (Fluidigm) and screened for reproducibility. The final assay panel consisted of 48

160 SNP loci, and details of panel development can be found in Online Resource 1. Oysters were genotyped on a 48 x 48

161 Dynamic Array IFC (Fluidigm) using the manufacturer's recommended protocol. Briefly, pre-amplification PCR

162 was done first using specific target amplification (STA) primers for each SNP locus to standardize the quantity of

163 starting DNA template for each sample before input into the SNPtype assay reaction (see Online Resource 2 for

164 primer sequences). The STA products were diluted 1:100 in DNA Suspension Buffer (Teknova, Inc., Hollister, CA).

165 SNPtype assay reactions using the ASP primers (see Online Resource 2 for primer sequences) were performed on a

166 Fluidigm IFC-1 cycler using the manufacturer's recommended protocol and the diluted STA products as template on

167 a 48 x 48 Dynamic Array IFC, which genotypes 47 individuals plus one blank control and 48 SNP loci

168 simultaneously. Resulting fluorescence signals were recorded on a BioMark HD and data were processed using the

169 SNP GENOTYPING ANALYsis 4.1.2 software (Fluidigm, San Francisco, CA) using a k-means clustering algorithm.

170 The confidence level for clustering was set at $65 \%$, as recommended by the manufacturer, and cluster membership

171 was verified by eye. Samples that had relative fluorescence values below 0.3 were invalidated and the data were re-

172 clustered. Ambiguous genotypes, defined as individual fluorescence values that were far from other genotype

173 clusters or half way between two clusters, were excluded to minimize genotyping errors. During marker

174 development, 141 individuals were run twice, and consistent results were obtained between replicate runs. There

175 was variance in the fluorescence values for the individuals run twice, but the genotype of each individual was

176 consistent between the duplicate runs. Of the 48 loci chosen for our SNP panel, one locus was chosen as a duplicate

177 to serve as an analytical control to assess reproducibility. The duplicate locus was removed from the data before

178 downstream analyses were performed. Due to reproducibility issues only 41 loci were used in the statistical analyses

179 (see Online Resource 1)

180 STATISTICAL ANALYSIS

181 Population genetic summary statistics were calculated for the data within and between sampled groups.

182 Oyster genotypes were checked for conformance to the expectations of Hardy-Weinberg Equilibrium (HWE) using

183 exact tests implemented in PEGAS 0.9 (Paradis, 2010) in R 3.4.0 (R Core Team, 2017). Individual locus F-statistics 


\section{Turley et al. Interannual oyster recruitment}

184 were calculated as described by Weir and Cockerham (1984) in HIERFSTAT 0.01-14 (Goudet, 2014) in R. In

185 addition, minor allele frequencies were calculated for each SNP locus to assess rare alleles in a sampled group. Tests

186 for genotypic linkage equilibrium between pairs of loci were conducted using the index of association described by

187 Brown et al. (1980) in the R package PoPPR 1.1.4 (Kamvar et al. 2014). Linkage between loci within or among

188 samples was used to assess independent assortment or if significant inbreeding occurred. Pairwise $\mathrm{F}_{\mathrm{ST}}$ values across

189 all loci were calculated in ARLEQUIN 3.3.2.2 (Excoffier and Lischer 2010). These pairwise F-statistics were used to

190 determine within and among sample genetic variation to resolve potential sample relationships. Because there were

191 a large number of individuals, loci, and tests performed, type I error using a standard p-value (alpha) would bias our

192 interpretation of the results. To control the false discovery rate, an initial alpha of 0.05 was adjusted using the

193 Benjamini-Yekutieli (2001) method (Online Resource 1).

194 Multivariate analyses were used to explore non-random patterns of genetic variability within and among

195 samples in a semi-spatial context. The analysis was semi-spatial because no explicit spatial data were used;

196 however, individuals were identified by the geographic group in which they were collected. Principal component

197 analysis (PCA) was used to investigate covariance across individual oysters and between the individuals' allele calls

198 using methods implemented by the R package ADEGENET 1.4.2 (Jombart 2008). For each column, the mean of the

199 data was subtracted and divided by its standard deviation and missing allele calls were replaced with the column

200 mean. There were 720 missing allele calls substituted out of 56,580 total allele calls due to failed fluorescence or

201 ambiguous clustering ( 1.3\% missing data). The results of the PCA summarizes covariance between individual

202 genotypic data and were used to examine differences on an individual, rather than on a population level. The

203 advantage of PCA is that it does not make assumptions about the relationships within the data, such as HWE and

204 linkage equilibrium, like the other population genetic analyses that were performed in this study.

205 Bayesian clustering methods were performed to determine the probable number of population clusters and

206 to determine likely cluster membership for each oyster. Individual genotypes were clustered using STRUCTURE 2.3.4

207 (Pritchard et al. 2000), and were performed with correlated allele frequencies, admixture, and sampling location

208 used as a prior. Simulations were run for 100,000 iterations with 50,000 initial steps discarded while k, number of

209 putative populations, was set from one through ten at four iterations per $\mathrm{k}$ as recommended by the software

210 developer. The most likely value of $\mathrm{k}$ was determined using the $\Delta \mathrm{k}$ method described by Evanno et al. (2005) and

211 implemented in Structure HarVester (Earl and VonHoldt 2012). In addition, GenELAND 4.0.5 (Guillot et al. 
Turley et al. Interannual oyster recruitment

212 2005) implemented in R was used to perform spatially-dependent clustering. Geographic coordinates were included

213 as a prior distribution in the model and only samples that we were confident about their location were included in

214 the spatial analyses. Four different subsets of the data were run for six iterations per set to account for possible

215 cryptic regional population clusters and the highest mean log-likelihood of the data was used to determine the most

216 likely run. GENELAND was run for 100,000 iterations with a thinning of 100, with $\mathrm{k}$ set from one to ten, and using

217 the correlated allele frequencies model. The runs were post-processed by discarding the initial 200 iterations kept

218 from the thinning. Both Structure and GENELAND use a similar Bayesian clustering algorithm that assumes putative

219 populations conform to expected proportions of HWE and linkage equilibrium.

\section{RESULTS}

In total, 744 individuals were genotyped across 48 loci. Of these 48 loci, one was an analytical control and

222 six were excluded due to poor fluorescence or ambiguous calls, leaving 41 markers for population genetic analysis

223 (see Online Resource 1). Across all samples, expected heterozygosity ranged from 0.004 for locus prp-198 to 0.50

224 for locus $\mathrm{cm} 4-346$ (Table 1). Within samples, the $\mathrm{NEH}^{\circledR}$ sample had the lowest mean expected heterozygosity at

2250.24 , while the LR13 spat sample had the highest mean expected heterozygosity of 0.33 . There were 14 loci that

226 exhibited deviations from the expectations of Hardy-Weinberg Equilibrium (HWE) among the 41 loci (Table S1);

227 however, no loci were out of HWE across all samples. Three loci, ba-83, nss1-228, and rpo-422, had significant

228 deviations from HWE in seven, six, and five of the nine samples, respectively. Two loci, mych-289 and prp-198,

229 were monomorphic in more than half of the samples (Table S1). Within samples, the number of loci out of HWE

230 ranged from zero in LR to eight in the LR13 with a median of four loci out of HWE across all samples (Table S1).

231 The linkage analysis indicated the reference samples LR, TI, and $\mathrm{NEH}^{\circledR}$ had significant global linkage $(\mathrm{p}<0.002, \mathrm{p}$

$232<0.001$, and $\mathrm{p}<0.001$, respectively, Table S2); however, no pairs of loci were significantly linked across all

233 samples. The locus pairs nss-417 and hsp6-205, rp19-451 and hsp6-205, and rpl9-451and nss-417 had large

234 estimated linkage values indicating low probability of independent assortment in both the LR reference and LR13

235 spat samples; however, these pairs were not linked in any other samples. Additionally, the linked loci had significant

236 heterozygote excesses in the LR13 sample $(\mathrm{p}<0.001)$, but not the LR sample. A pairwise relatedness analysis

237 demonstrated that LR13 had a higher than expected levels of relatedness compared to LR and LR14 (Figure S1).

238 Population pairwise $\mathrm{F}_{\mathrm{ST}}$ values were summarized in Table 2. Adult oysters were sampled from multiple

239 locations within the Lafayette, Elizabeth, and James Rivers and pairwise $\mathrm{F}_{\mathrm{ST}}$ values were first calculated between 
Turley et al. Interannual oyster recruitment

240 sampling locations within each river. We found that all within river comparisons were non-significant $(\mathrm{p}>0.01)$, 241 therefore within river adult samples were combined for all subsequent analyses. The $\mathrm{F}_{\mathrm{ST}}$ values were significantly

242 different between 26 out of 36 total pairwise comparisons ( $p<0.01$ ), and had a median value of 0.02 ranging from -

$2430.04(\mathrm{p}=0.99)$ between TI and RR and $0.14(\mathrm{p}<0.01)$ between TI and NEH ${ }^{\circledR}$. The F $\mathrm{F}_{\mathrm{ST}}$ values calculated between

$244 \mathrm{NEH}^{\circledR}$ samples and all other samples were elevated relative to other pairwise comparisons, ranging from a minimum

$245 \mathrm{~F}_{\mathrm{ST}}$ of 0.10 compared with LR14, ER, and JR to a maximum $\mathrm{F}_{\mathrm{ST}}$ of 0.14 compared to both the RR and TI samples

246 and all comparisons were significantly different $(\mathrm{p}<0.01)$. The median $\mathrm{F}_{\mathrm{ST}}$ for $\mathrm{NEH}^{\circledR}$ is 0.12 and the median of all

247 other comparisons without $\mathrm{NEH}^{\circledR}$ is 0.01 , an order of magnitude difference. The LR sample was significantly

248 different from all other samples with median value of 0.01 with the exception of $\mathrm{TI}\left(\mathrm{F}_{\mathrm{ST}}=-0.02, \mathrm{p}=1.00\right)$. The spat

249 samples LR13 and LR14 were significantly different from each other $\left(F_{S T}=0.03, p<0.01\right)$. The LR13 spat were

250 significantly different from the LR reference sample $\left(\mathrm{F}_{\mathrm{ST}}=0.01, \mathrm{p}=0.01\right)$ but not $\mathrm{TI}\left(\mathrm{F}_{\mathrm{ST}}=-0.03, \mathrm{p}=1.00\right)$. The

251 LR14 spat were not significantly different from ER, JR, or TI $\left(\mathrm{F}_{\mathrm{ST}} \sim 0, \mathrm{p}=1.00\right)$; however, they were significantly

252 different from the LR reference sample $\left(\mathrm{F}_{\mathrm{ST}}=0.01, \mathrm{p}<0.01\right)$.

253 The PCA resolved several clusters of individuals. For reference group samples, the PCA indicated the

254 presence of discrete clusters of individuals that were partially reflective of the geographic relationships of the

255 samples in the Chesapeake Bay. The first two principal components retained from the PCA explained 6.5\% and

$2564.8 \%$ of the variance in the individual genotypic data (Figure $2 \mathrm{a}$ ). The $\mathrm{NEH}^{\circledR}$ individuals were separated from all

257 other genotyped individuals with minimal overlap in component space. The individuals from ER, JR, and GR

258 clustered together, while the majority of individuals from RR and TI clustered together. Individuals from LR had a

259 wider distribution, situated in component space among several clusters including space occupied by RR and TI, and

260 in component space occupied by ER, JR, and GR. The spat samples LR13 and LR14 were separated from each other

261 with minimal overlap. The LR13 sample had a wider distribution occupying space primarily with LR and some with

262 ER, JR, and GR. While LR14 had a narrower distribution, sharing component space primarily with ER, JR, and GR.

263 The results of the different STRUCTURE simulations had similar results and only the simulations using

264 correlated allele frequencies and admixture are discussed. The results of the STRUCTURE simulations converged on

265 three clusters (mean Ln likelihood = -25136) with individual oysters from RR and TI in cluster one; $\mathrm{NEH}^{\circledR}$

266 individuals exclusively in cluster two; while ER, JR, and GR individuals in cluster three (Figure 2b). The individual

267 adults from LR were assigned to multiple clusters and showed evidence of admixture between clusters one and 
Turley et al. Interannual oyster recruitment

three. The majority of LR individuals (60\%, 32 of 53 oysters) were assigned to cluster three and the remainder were assigned to cluster one with the all RR and TI individuals. The majority of LR13 individuals (75\%, 74 of 99 spat) were assigned to cluster one with RR and TI reference samples, while remaining LR13 spat were assigned to cluster one, which includes individuals sampled from the JR, ER, LR and GR. Unlike the LR13, which had individuals assigned to different clusters, the spat in the LR14 sample were exclusively assigned to cluster one. The STRUCTURE 273 simulation results were qualitatively similar to the results from the PCA. When spatial data was explicitly taken into account, simulations performed in GENELAND resolved four population clusters in the Chesapeake Bay when all individuals were included. Overall, these results are similar to the PCA and STRUCTURE results except that results from GENELAND put the RR and TI samples into separate clusters (Figure S2). The discrepancy between these results is likely due to the spatial data used as priors in the GENELAND model input. In a second analysis including only those individuals sampled within the Lafayette River (i.e., LR, LR13, and LR14), an upriver section, eastward away from the mouth of the Lafayette, contains a cluster with $100 \%$ of the individuals from the LR reference sample, 91\% of the LR13, and 31\% of the LR14 individual spat (Figure 3). A second cluster located downriver and including the mouth of the Lafayette, which is connected to the Elizabeth River, contains 69\% of LR14 and 9\% of LR13 individual spat.

Within the Lafayette River, the temporal and spatial patterns of post-larval oyster settlement based on the

284 shell-string surveys contrasted with patterns of spat recruitment based on the spat-collectors. Within each year, the 285 timing of settlement among shell-string sites was similar. Both the temporal and spatial patterns, however, varied 286 between 2013 and 2014 (Figure S3). In the 2013 shell-string survey, post-larval oyster settlement was initially 287 observed in mid-June and steadily increased with a peak in early August (Figure 4). By September of 2013, the 288 supply of spat had decreased to levels that were observed in the beginning of the spawning in June. In 2014, the first 289 post-larval oysters were not observed until mid-July, the peak of post-larval settlement occurred in early August, and 290 a second peak was observed in early-September. The spatial pattern of settlement also differed between years (Table 291 S3). In 2013 the majority of the post-larval oysters were recovered mid-river and upriver with few settling at the 292 mouth, while in 2014 the majority of post-larval oysters were recovered near the mouth with some settlement 293 upriver (Figure S3). The spatial pattern of recruitment was inferred based on the 2013 and 2014 spat-collector data. 294 The total number of recruited spat in 2013 was 937 from 51 spat collectors (Figure 5a). The majority of the spat 295 were collected near the mouth of the river (90\%), very few were collected mid-river (6\%) and up-river (4\%). In 


\section{Turley et al. Interannual oyster recruitment}

2014, the number of recruited spat was higher; 3132 spat were collected from 36 spat collectors (Figure 5b). Similar to 2013, the majority of recruited spat were from spat collectors returned from near the mouth of the river (94\%), and few were collected from mid-river (4\%) and up-river (2\%).

\section{DISCUSSION}

We developed a SNP panel for use in a rapid, high-throughput platform that is easily scalable for genetic marker-based management studies of any species. Previous investigations of $C$. virginica to assess regional population connectivity predominantly relied on mtDNA or microsatellite markers (Milbury et al. 2004, Hare et al. 2006, Carlsson et al. 2008). Our use of SNPs overcame many of the limitations exhibited by other molecular markers, particularly those of microsatellites (Morin et al. 2004, Garvin et al. 2010). Oysters have high levels of intra-specific polymorphism, and as a result null alleles and homoplasy are pervasive problems when using microsatellites (Launey and Hedgecock 2001, McGoldrick et al. 2000, Reece et al. 2004). Furthermore, SNPs are easily transferable between laboratories because they are less susceptible to subjective interpretation of fluorescence peaks, which is a common problem with standard microsatellite techniques. The SNP panel developed for this study has utility in C. virginica aquaculture and fishery research context, including stock identification, monitoring of diversity, and inbreeding assessment.

Our results demonstrate that the SNP panel developed for this project can resolve genetic differences on small spatial scales, which is necessary for use in recruitment studies and restoration management applications. The SNP panel consisting of 41 loci resolved significant differences between adult oysters from the Lafayette, Elizabeth, and James Rivers. We expected a priori that there would be little difference between oysters from these sites because these rivers are hydrodynamic connected (Shen et al. 1999) and connectivity is within the time scale of oyster pelagic larval duration (Kennedy 1996). Additionally, our SNP panel resolved significant differences between oysters sampled from the lower Chesapeake Bay and those collected from the Rappahannock and Great Wicomico Rivers, which are mid-Bay and more than $70 \mathrm{~km}$ distant. Previous work using eight microsatellite markers resolved significant differences within the Chesapeake Bay, and demonstrated a subtle pattern of isolation by distance on spatial scales similar to the larger geographic scale encompassed by our study (Rose et al. 2006). The statistical power of the 41 SNPs used by this study is comparable to that of the eight microsatellites used by Rose et al. (2006) when trying to resolve moderate levels of population differentiation ( $\mathrm{F}_{\mathrm{ST}} \sim 0.01$, Morin et al. 2009). Thus, our SNP panel was an adequate tool to evaluate annual oyster recruitment on small spatial scales. 
Turley et al. Interannual oyster recruitment

The reproductive contribution of restoration oysters newly recruiting within the Lafayette River was

325 assessed using the SNP panel developed for this study. Our panel was sufficient to resolve significant genetic

326 differences between the hatchery-bred $\mathrm{NEH}^{\circledR}$ oysters and field-sampled oysters. However, neither $\mathrm{NEH}^{\circledR}$ offspring

327 nor $\mathrm{NEH}^{\circledR}$-hybrid spat were detected in the samples from the Lafayette in 2014 (Figure 2b). We do not interpret our

328 results to suggest that the $\mathrm{NEH}^{\circledR}$ oysters introduced by CBF did not spawn nor contribute progeny during the time

329 span of our study. Rather, it is likely $\mathrm{NEH}^{\circledR}$ oysters spawned, but our sampling did not capture $\mathrm{NEH}^{\circledR}$ derived spat.

330 Approximately 114,000 $\mathrm{NEH}^{\circledR}$ oysters were planted in the Lafayette River in 2013 for this project, and the estimated

331 census size is $3.4 \times 10^{9}$ oysters in the James River, and 3.0x $10^{6}$ oysters in the Elizabeth and Lafayette Rivers

332 combined (Mann et al. 2015). The likelihood of detecting a genetic signal of $\mathrm{NEH}^{\circledR}$ progeny was low because the

333 signal could be obscured by resident-oyster reproductive output. Wilbur et al. (2005) made a similar suggestion to

334 explain an absence of a genetic signal from restoration scallops amidst signals from wild scallops in a Florida

335 estuary. The Tangier Island oysters, the second restoration line used in this study, were not significantly different

336 from the resident adult oysters sampled in the Lafayette, Elizabeth, or James Rivers. This lack of significant

337 differentiation was not expected considering the geographic distance (greater than $100 \mathrm{~km}$ ) between the lower

338 Chesapeake Bay and Tangier Island; however, the history of restoration and oyster seed-stock movement throughout

339 Chesapeake Bay provides a possible explanation. The CBF has been introducing oysters into the Lafayette and

340 Elizabeth Rivers from a variety of sources around the Chesapeake Bay since 1999 (T. Leggett, personal

341 communication). It is likely that significant genetic differences between oysters residing near Tangier Island and

342 oysters in the lower Chesapeake Bay once existed due to isolation by distance (Rose et al. 2006) but may have been

343 diluted out as a result of CBF restoration plantings.

344 Despite the paucity of data that the experimentally planted oysters contributed to the 2014 recruitment, our

345 analyses reveal a potential influence of oysters genetically similar to the RR reference samples (Figure 2).

346 According to records from the CBF, about 1.1 million Rappahannock oysters were introduced to the Tanner's Point

347 and Larchmont reefs in the Lafayette River during the course of restoration activities in 2011 and 2012 (Table 3).

348 Our analyses suggest that the Rappahannock oysters planted in the Lafayette reproductively contributed to the

349 Lafayette genepool and influenced the genotypic signature for some of the 2013 spat in this study. However,

350 variation in reproductive success can lead to an overestimation of the long-term contributions by restoration oysters

351 (Hedgecock and Pudovkin 2011), and this may be the case with the Rappahannock oysters planted by the CBF. 


\section{Turley et al. Interannual oyster recruitment}

352 Thus, while our results demonstrate a contribution of oysters that are genetically similar to RR, a sustained

353 contribution of Rappahannock oysters cannot be inferred from this data. Therefore, a monitoring strategy to obtain

354 cohorts from specific reproductive events over multiple years would be sufficient to parse interannual variation in

355 larval demographics.

356 The results of our study suggest that there were variable sources for spat recruitment within the Lafayette

357 River on interannual timescales. Spat collected in 2013 had genotypic signatures that were more closely related to

358 reference oysters sampled from the Lafayette River, and the spat were significantly different from the reference

359 samples collected in adjacent rivers. These results indicate that 2013 was a retentive year in which the prevailing

360 reproductive contribution to recruitment was from within the Lafayette River and there was low dispersal of larvae

361 produced in Elizabeth or James Rivers. In contrast, the spat collected in 2014 had a different genotypic signature

362 similar to the reference oysters collected from the Elizabeth, and James Rivers. We interpret our results to suggest

363 that the 2014 spat were a mixture of larvae spawned in the Lafayette and the adjacent rivers. The pattern of

364 recruitment in which more spat are found near the mouth of the Lafayette was similar between years (Figure 5);

365 however, the relative contribution of sources was different (Figure 3). Differences in the observed interannual source

366 populations for the recruiting spat were likely a consequence of variance in reproductive success as well as variance

367 in larval survival (Hedgecock 1982). For example, $C$. virginica are highly fecund, broadcast spawners whose pelagic

368 larvae experience high mortality, and variations in these processes differentially impact annual reproductive success.

369 As a result, variable contributions by different source populations to new recruits influences their resulting

370 genotypic signatures (Hedgecock and Pudovkin 2011). The changes to reproductive success can be associated with

371 intrinsic demographic variability such as fluctuations in fecundity, but other factors may also be important such as

372 changes to the physical environment encountered during the spawning season.

373 To explore a potential physical mechanism for the observed variance in recruitment patterns and genotypic

374 signatures between 2013 and 2014, wind data from Norfolk Naval Air Station, VA (Network ID:

375 GHCND:USW00013750, obtained from NOAA National Climatic Data Center) were examined. Winds were

376 considered because they are an important mechanism for physical mixing of relatively shallow water masses similar

377 to the lower Chesapeake Bay. We found that wind patterns in the summer months before and during the peak post-

378 larval settlement differed between 2013 and 2014 (Figure 4). In 2013, the prevailing winds blew from the south-

379 southwest (Figures 4 and 5a), possibly forcing water out of the Elizabeth River into the James River near Newport 
Turley et al. Interannual oyster recruitment

News, Virginia and creating a local sea-surface-height low in which water from the Lafayette River could move out in response to a horizontal pressure gradient. As surface waters in the Lafayette River moved out, oyster larvae would be dispersed, and larvae would possibly be restricted from moving into the Lafayette except in deeper tidal flow. However, bivalve larvae in laboratory settings demonstrate vertical movement in response to steep salinity gradients, restricting larval distribution below the halocline and limiting deeper, tidal dispersal (Mann et al. 1991). Alternatively, winds out of the southwest could have forced surface waters toward the Lafayette River creating a local sea-surface-height high, restricting larval dispersal due to reduced surface advection against a horizontal pressure gradient, and forcing locally produced larvae to settle within the river.

In contrast, 2014 exhibited different wind patterns the weeks before and during peak post-larval settlement (Figures 4 and 5b). The winds were weaker on average and coming from both the south-southwest and eastnortheast in July and August, respectively. Furthermore, the weekly zonal winds (u, Figure 4) in July and August 2014 demonstrated an alternating east-to-west pattern that was distinct from the autocorrelated pattern in 2013 for

392 the same months (Figure 4). The shifting winds in 2014 likely facilitated mixing of local water masses and 393 concurrent planktonic larvae contributing to the genotypic signal observed for the 2014 spat. The mesohaline James

394 River tidal front weakens during ebb tide and mixes with waters from the polyhaline Elizabeth and Lafayette Rivers 395 (Shen et al. 1999). The mixing facilitates expansion and dispersal of phytoplankton blooms initiated in either the 396 Lafayette, Elizabeth, or James Rivers across this region in about 20 days (Mulholland et al. 2009, Morse et al. 2011).

397 The temporal scale of the circulation patterns within the lower Chesapeake Bay is well within the pelagic larval 398 duration of oysters (Kennedy 1996) and oyster reef connectivity between these rivers is a reasonable hypothesis. We 399 suggest that the contribution of oysters spawned in disparate regions of the lower Chesapeake Bay to annual oyster 400 recruitment in the Lafayette River varies on interannual time scales and is partially dependent upon the winds during 401 the summer spawning season. Future work should investigate the interaction of wind forcing, hydrodynamics, and 402 larval dispersal and settlement in this region.

403 During peak oyster spawning months in the summer, the Chesapeake Bay can be host to several potentially 404 harmful algal species. The harmful algal bloom (HAB) events in the lower Chesapeake Bay during 2013 and 2014 405 were different. Specifically, the duration and geographic extent of the annual bloom of Margalefidinium (previously 406 known as Cochlodinium) polykrikoides varied between these two years. In 2013, the M. polykrikoides bloom was 407 first observed in the Lafayette on August $9^{\text {th }}$ and lasted in the James, Elizabeth and Lafayette Rivers region through 
Turley et al. Interannual oyster recruitment

408 September $6^{\text {th }}$. The effects of $M$. polykrikoides on adult and larval oysters in the field are not well understood.

409 Laboratory studies, however, have demonstrated that adult oysters will close their shells to possibly reduce toxin

410 exposure (Hégaret et al. 2007). Larval oysters exposed to M. polykrikoides in laboratory studies have demonstrated

411 increased mortality possibly due to factors including toxicity to HAB by-products (Tang and Gobler 2009,

412 Mulholland et al. 2009, Reece et al. 2012). It is possible that the 2013 bloom either restricted further spawning as

413 adults limited exposure by closing their shells or that larvae in the plankton suffered high mortalities reducing the

414 supply of oyster larvae into the Lafayette mid-August through early September. In contrast during 2014, the $M$.

415 polykrikoides bloom in this region was limited both the spatial and temporal extent (Reece 2014). Few HAB

416 samples were collected in the region from small bloom patches in mid-June through early July (Reece 2013, 2014,

417 Marshall and Egerton 2013, 2014), before the peak timing of post-larval settlement within the river (Figure 4). The

418 reduced $\mathrm{HAB}$ activity might have been partially contributed for the overall increased spat recruitment in 2014 as

419 quantified by the spat collectors (Figure 5b). Unfortunately, our data cannot resolve the dynamics between timing of

420 larval settlement, spat source, and HAB activity in the region; however, our results provide a tantalizing suggestion

421 for recruitment control by HABs in the lower Chesapeake Bay that deserves further study.

422 Our results offer support for larval settlement projections produced by the Sisson and Shen (2012)

423 connectivity model. Overall, the model output demonstrates that oyster larvae spawned in the Lafayette River will

424 settle out in the upper parts of the river away from the mouth leading to the rest of the lower Chesapeake Bay

425 (Figure S4). The results from 2013 exhibit a similar retentive capacity of the Lafayette such that larvae produced in

426 the river can settle within the river (Figure 3). A limitation of our study was that no spat collectors were placed

427 outside the Lafayette to identify dispersal out of the river; however, several spat collectors in both 2013 and 2014

428 were sampled at the mouth of the Lafayette. The results of the collectors at the mouth demonstrate genotypic

429 signatures that were both similar to the Lafayette reference sample in 2013 and the adjacent rivers, while the 2014

430 spat collector results at the mouth had a more cosmopolitan genotypic signature. The explanation for the discrepancy

431 between the model projections and the field results were likely due to several factors. For example, the model was

432 initialized with winds from 2008, a year with wind patterns more similar to those observed in 2013. The model

433 cannot represent the wind variability present both in 2013 and 2014. Because the winds in 2013 were more similar

434 to 2008 used to initialize the model, the observed retentive capacity of the Lafayette during 2013 compares well with

435 the expected settlement projections produced by the model. In addition, the model did not simulate the settlement of 


\section{Turley et al. Interannual oyster recruitment}

436 larvae produced outside the Lafayette River, and as a result the relative contribution by different rivers in the Lower

437 Chesapeake Bay to the Lafayette cannot be assessed from the model output. Lastly, the connectivity model does not

438 explicitly represent conditions within the estuary important for larval survival, settlement, and spat recruitment thus

439 limiting the comparisons between observations and model output. In reality, the regions of highest recruitment

440 projected by the model (Figure S4), upriver away from the mouth, are also the areas that have the lowest recovery

441 per spat-collector (Figure 5). The upriver regions are not suitable for spat survival because these areas have little

442 hard substrate for attachment, suspended sediments from runoff smother spat, and high heat during low tides in the

443 summer spawning season easily desiccates spat.

CONCLUSIONS

Restoration projects, which introduce live organisms, make the assumption that planted individuals will add

to the spawning potential of local populations and contribute to subsequent recruitment. The overall aim of this

447 study was to test whether restoration efforts impacted the annual oyster recruitment such that genetic contributions

448 could be detected within the Lafayette River, VA. Our study failed to detect any contribution in newly recruiting

449 oysters from the two experimentally planted oyster strains chosen to be easily identified using molecular genetic

450 methods. We did find evidence to suggest that oysters from the Rappahannock River previously planted for

451 restoration had contributed to recruitment within the Lafayette River. The geographic distance between these rivers

452 precludes direct dispersal, and as a result we can conclude that the observed spat genotypes are due to restoration

453 activities. Furthermore, our research demonstrated that the source populations for newly recruiting oyster spat varies

454 on interannual timescales within the Lafayette River. Thus, we suggest that ecological investigations for

455 management objectives into sessile, broadcast-spawning estuarine species should consider the interannual

456 differences in larval dispersal and recruitment.

457 We identified several potential factors influencing the source and magnitude of oyster settlement and

458 recruitment within the Lafayette River. Due to the timing of the blooms, HABs in 2013 could not influence the post-

459 larval oysters settling in the Lafayette until the second week of August. It is more likely that the winds influenced

460 the hydrodynamics, precluding significant contributions of larvae spawned outside the Lafayette; however, some

4612013 spat were similar to oysters from outside the Lafayette. It is possible that the hydrodynamics in 2013 were

462 sufficient for oysters spawned outside the Lafayette to settle in the Lafayette, but HABs may have exerted a greater

463 control on post-larval survival in the late summer. In comparison, HABs in 2014 were early and limited in extent, 


\section{Turley et al. Interannual oyster recruitment}

464 while shifting zonal winds provided ample energy to physically mix the water masses and the resident plankton in 465 the lower Chesapeake Bay. Observations of the timing of spawning in the lower Chesapeake Bay, identification of

466 specific cohort settlement timing, and plankton community composition would help to resolve the dynamics

467 between oyster larval survival and HABs. We do not to intimate that the factors mentioned are the only influences, 468 nor the most influential for settlement and recruitment; however, the preponderance of data lead us to suggest that 469 the potential linkages mentioned are relevant on interannual timescales. 


\section{Turley et al. Interannual oyster recruitment}

470 Funding: Virginia Sea Grant for provided program development funds. Also, the Tidewater Oyster Growers

471 Association gave B. Turley a fellowship in support for this research.

472

473 Conflict of Interest: The authors declare that they have no conflict of interest.

474

475 Data availability: The datasets generated by this study are available from corresponding author upon request. 
Turley et al. Interannual oyster recruitment

Literature Cited

477

Benjamini Y, Yekutieli D (2001) The control of the false discovery rate in multiple testing under dependency. The Annals of Statistics 29(4) 1165-1188.

Brown AH, Feldman MW, Nevo E (1980) Multilocus Structure of Natural Populations of Hordeum spontaneum. Genetics 96(2):523-536.

Buroker NE (1983) Population genetics of American oyster Crassostrea virginica along the Atlantic coast and the Gulf of Mexico. Marine Biology 75:99-112.

Carlsson J, Carnegie RB, Cordes JF, Hare MP, Leggett AT, Reece KS (2008) Evaluating Recruitment Contribution of a Selectively Bred Aquaculture Line of the Oyster, Crassostrea virginica used in Restoration Efforts. Journal of Shellfish Research 27(5):1117-1124. https://doi.org/10.2983/0730-8000-27.5.1117.

Earl D, VonHoldt BM (2012) STRUCTURE HARVESTER: A website and program for visualizing STRUCTURE output and implementing the Evanno method. Conservation Genetics Resources 4(2):359-361. https://doi.org/10.1007/s12686-011-9548-7.

Evanno G, Regnaut S, Goudet J (2005) Detecting the number of clusters of individuals using the software STRUCTURE: A simulation study. Molecular Ecology 14(8):2611-2620. https://doi.org/10.1111/j.1365294X.2005.02553.x.

Excoffier L, Lischer HEL (2010) Arlequin suite ver 3.5: A new series of programs to perform population genetics analyses under Linux and Windows. Molecular Ecology Resources 10(3):564-567. https://doi.org/10.1111/j.1755-0998.2010.02847.x.

Foll M, Gaggiotti O (2008) A genome-scan method to identify selected loci appropriate for both dominant and codominant markers: A Bayesian perspective. Genetics 180(2):977-993. https://doi.org/10.1534/genetics.108.092221.

Garvin MR, Saitoh K, Gharrett AJ (2010) Application of single nucleotide polymorphisms to non-model species: A technical review. Molecular Ecology Resources 10(6):915-934. https://doi.org/10.1111/j.17550998.2010.02891.x.

Goudet, J (2014) hierfstat: Estimation and tests of hierarchical F-statistics, ver. 0.04-14. R package.

Grabowski JH, Brumbaugh RD, Conrad RF, Keeler AG, Opaluch JJ, Peterson CH et al (2012) Economic Valuation of Ecosystem Services Provided by Oyster Reefs. BioScience 62(10):900-909. https://doi.org/10.1525/bio.2012.62.10.10.

Guillot G, Mortier F, Estoup A (2005) GENELAND: A computer package for landscape genetics. Molecular Ecology Notes 5(3):712-715. https://doi.org/10.1111/j.1471-8286.2005.01031.x.

Hare MP, Allen SK, Bloomer P, Camara MD, Carnegie RB, Murfree J et al (2006) A genetic test for recruitment enhancement in Chesapeake Bay oysters, Crassostrea virginica, after population supplementation with a disease tolerant strain. Conservation Genetics 7(5):717-734. https://doi.org/10.1007/s10592-005-9108-3.

Hedgecock, D (1982) Genetic Consequences of Larval Retention: Theoretical and Methodological Aspects. In V. S. Kennedy (Ed.) Estuarine Comparisons (pp. 553-568). New York: Academic Press. 
Turley et al. Interannual oyster recruitment

512

513

514

515

516

517

518

519

520

521

522

523

524

525

526

527

528

529

530

531

532

533

534

535

536

537

538

539

540

541

542

543

544

545

546

547

548

Hedgecock D, Pudovkin AI (2011) Sweepstakes Reproductive Success In Highly Fecund Marine Fish And Shellfish: A Review And Commentary. Bulletin of Marine Science 87(4):971-1002. https://doi.org/10.5343/bms.2010.1051.

Hégaret H, Wikfors GH, Shumway SE (2007) Diverse Feeding Responses of Five Species of Bivalve Mollusc When Exposed to Three Species of Harmful Algae. Journal of Shellfish Research 26(2):549-559. https://doi.org/10.2983/0730-8000(2007)26[549:DFROFS]2.0.CO;2.

Jackson JBC, Kirby MX, Berger WH, Bjorndal KA, Botsford LW, Bourque BJ et al (2001) Historical Overfishing and the Recent Collapse of Coastal Ecosystems. Science 293(5530):629-637.

Jombart T (2008) adegenet: a R package for the multivariate analysis of genetic markers. Bioinformatics 24(11):1403-1405.

Kamvar ZN, Tabima JF, Grünwald NJ (2014) Poppr: an R package for genetic analysis of populations with clonal, partially clonal, and/or sexual reproduction. PeerJ 2:e281.

Kennedy VS (1996) Biology of Larvae and Spat. In VS Kennedy, RIE Newell, A Eble (Eds.) The Eastern Oyster: Crassostrea virginica (pp. 371-422). College Park, MD.

Kopelman NM, Mayzel J, Jakobsson M, Rosenberg NA, Mayrose I (2015) Clumpak: a program for identifying clustering modes and packaging population structure inferences across K. Molecular Ecology Resources 15(5):1179-1191. https://doi.org/10.1111/1755-0998.12387.

Launey S, Hedgecock D (2001) High genetic load in the Pacific oyster Crassostrea gigas. Genetics 159(1):255-265.

Mann R, Bernardita MC, Luckenbach MW (1991) Swimming rate and responses of larvae of three mactrid bivalves to salinity discontinuities. Marine Ecology Progress Series 68:257-269.

Mann R, Southworth M, Wesson, J (2011) Stock Assessment of Public Grounds and Sanctuaries in Virginia, Fall 2011. Gloucester Point, VA.

McGoldrick D, Hedgecock D, English LJ, Baoprasertkul P, Ward RD (2000) The transmission of microsatellite alleles in Australian and North American stocks of the Pacific oyster (Crassostrea gigas): selection and null alleles. Journal of Shellfish Research 19:779-788.

Milbury CA, Meritt DW, Newell RIE, Gaffney PM (2004) Mitochondrial DNA markers allow monitoring of oyster stock enhancement in the Chesapeake Bay. Marine Biology 145(2):351-359. https://doi.org/10.1007/s00227004-1312-z.

Morin PA, Luikart G, Wayne RK (2004) SNPs in ecology, evolution and conservation. Trends in Ecology and Evolution 19(4):208-216. https://doi.org/10.1016/j.tree.2004.01.009.

Morin PA, Martien KK, Taylor BL (2009) Assessing statistical power of SNPs for population structure and conservation studies. Molecular Ecology Resources 9(1):66-73. https://doi.org/10.1111/j.17550998.2008.02392.x.

Morse RE, Shen J, Blanco-Garcia JL, Hunley WS, Fentress S, Wiggins M, Mulholland MR (2011) Environmental and Physical Controls on the Formation and Transport of Blooms of the Dinoflagellate Cochlodinium polykrikoides Margalef in the Lower Chesapeake Bay and Its Tributaries. Estuaries and Coasts 34(5):10061025. https://doi.org/10.1007/s12237-011-9398-2. 
Turley et al. Interannual oyster recruitment

Mulholland MR, Morse RE, Boneillo GE, Bernhardt PW, Filippino KC, Procise LA et al (2009) Understanding causes and impacts of the dinoflagellate, Cochlodinium polykrikoides, blooms in the Chesapeake Bay. Estuaries and Coasts 32(4):734-747. https://doi.org/10.1007/s12237-009-9169-5.

North EW, Schlag Z, Hood RR, Li M, Zhong L, Gross T, Kennedy VS (2008) Vertical swimming behavior influences the dispersal of simulated oyster larvae in a coupled particle-tracking and hydrodynamic model of Chesapeake Bay. Marine Ecology Progress Series 359:99-115. https://doi.org/10.3354/meps07317.

Paradis E (2010) pegas: an R package for population genetics with an integrated-modular approach. Bioinformatics 26(3):419-420.

Pritchard JK, Stephens M, Donnelly, P (2000) Inference of population structure using multilocus genotype data. Genetics 155(2):945-959. https://doi.org/10.1111/j.1471-8286.2007.01758.x.

R Core Team (2015) R: A language and environment for statistical computing, ver. 3.1.3. Vienna, Austria: R Foundation for Statistical Computing.

Reece K (2014) Monitoring for HAB species in VA Waters of Chesapeake Bay during 2014: Emerging HAB species in Chesapeake Bay. Gloucester Point, VA.

Reece K (2013) Monitoring for HAB species in VA Waters of Chesapeake Bay during 2013: Emerging HAB species in Chesapeake Bay. Gloucester Point, VA.

Reece K, Ribeiro WL, Gaffney PM, Carnegie RB, Allen SK (2004) Microsatellite marker development and analysis in the eastern oyster (Crassostrea virginica): Confirmation of null alleles and non-mendelian segregation ratios. Journal of Heredity: 95(4):346-352. https://doi.org/10.1093/jhered/esh058.

Rose CG, Paynter KT, Hare MP (2006) Isolation by distance in the eastern oyster, Crassostrea virginica, in Chesapeake Bay. Journal of Heredity 97(2):158-170. https://doi.org/10.1093/jhered/esj019.

RStudio Team (2013) RStudio, ver. 0.98.978. Boston, MA: RStudio.

Selkoe KA, D'Aloia CC, Crandall ED, Iacchei M, Liggins L, Puritz JB et al (2016) A decade of seascape genetics: Contributions to basic and applied marine connectivity. Marine Ecology Progress Series 554:1-19. https://doi.org/10.3354/meps11792.

Shen J, Boon JD, Kuo AY (1999) A Modeling Study of a Tidal Intrusion Front and Its Impact on Larval Dispersion in the James River Estuary, Virginia. Estuaries 22(3):681. https://doi.org/10.2307/1353055.

Sisson GM, Shen J, Kim SC, Boon JD et al (1997) VIMS three-dimensional hydrodynamic-eutrophication model (HEM-3D): application of the hydrodynamic model to the York River system (Special Report in Applied Marine Science and Ocean Engineering No. 341).

Sisson GM, Shen J (2012) Modeling of Oyster Larval Connectivity for CBF in Support of NOAA's CommunityBased Restoration Program \& Restore America's Estuaries Oyster and Reef Balls on Sanctuary Reefs in MD and VA - Phase Three (Special Report No. 433 In Applied Marine Science and Ocean Engineering).

Southworth M, Mann R (2015) The Status of Virginia's Public Oyster Resource 2014. Gloucester Point, VA.

Tang YZ, Gobler CJ (2009) Cochlodinium polykrikoides blooms and clonal isolates from the northwest Atlantic coast cause rapid mortality in larvae of multiple bivalve species. Marine Biology 156(12):2601-2611. https://doi.org/10.1007/s00227-009-1285-z. 
Turley et al. Interannual oyster recruitment

586

587

588

589

590

591

592

593
Weir BS, Cockerham CC (1984) Estimating F-Statistics for the Analysis of Population Structure. Evolution 38(6):1358-1370.

Wilbur AE, Seyoum S, Bert TM, Arnold WS (2005) A genetic assessment of bay scallop (Argopecten irradians) restoration efforts in Florida's Gulf of Mexico coastal waters (USA). Conservation Genetics 6(1):111-122. https://doi.org/10.1007/s10592-004-7747-4.

Zhang L, Guo X (2010) Development and validation of single nucleotide polymorphism markers in the eastern oyster Crassostrea virginica Gmelin by mining ESTs and resequencing. Aquaculture 302(1-2):124-129. https://doi.org/10.1016/j.aquaculture.2010.02.012. 
Turley et al. Interannual oyster recruitment

595 Fig. 1 (a) Locations within the Chesapeake Bay where oyster samples were collected. G - Great Wicomico River; T

596 - Tangier Island; D - Deepwater Shoal, James River; W - Wreck Shoals, James River; C - Cruisers Rock, James

597 River; B - Eastern Branch, Elizabeth River; H - Hospital Point, Elizabeth River; L - Lafayette River. (b) Lafayette

598 River inset with shell-string locations labeled with $\mathrm{S}$ and river regions labeled 
TITLE: Multiple drivers of interannual oyster settlement and recruitment in the lower Chesapeake Bay JOURNAL: Conservation Genetics

AUTHORS: Brendan Turley, Kimberly Reece, Jian Shen, Jeong-Ho Lee, Ximing Guo, Jan McDowell

CORRESPONDING AUTHOR: Jan McDowell, Virginia Institute of Marine Science, mcdowell@vims.edu

\section{Figure 1}

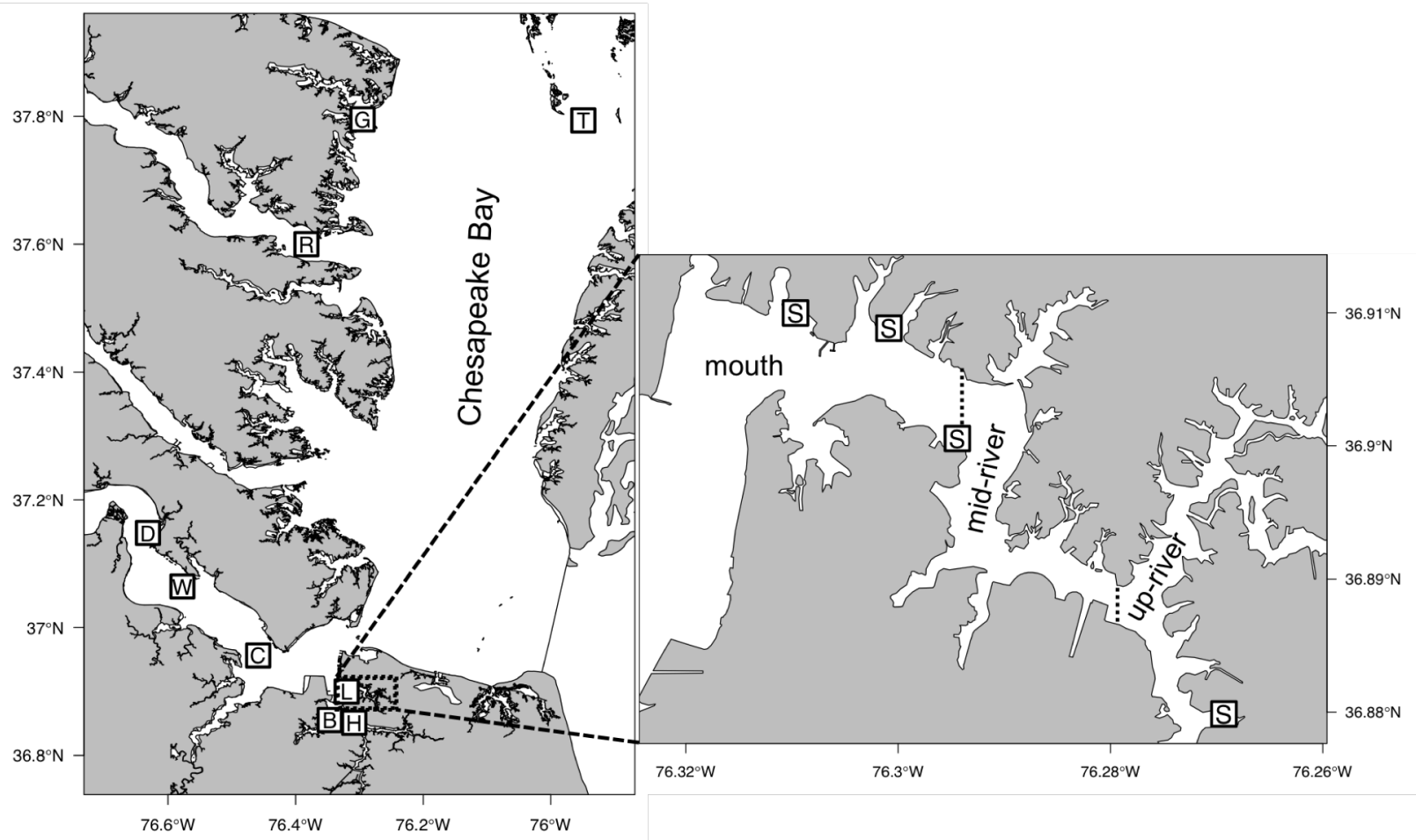




\section{Turley et al. Interannual oyster recruitment}

599 Fig. 2 (a) Principal Component Analysis results for samples grouped by sampling group. Each point represents one

600 individual oyster genotype. Variance explained for principal component one and two are in parenthesis on $\mathrm{x}$ and $\mathrm{y}$

601 axes, respectively. (b) Structure analysis results where three clusters $(k=3)$ is the most likely result; vertical bars

602 indicate posterior probabilities of cluster membership for individual oyster genotypes. Cluster designation starts at

603 the top and moves down; cluster one is indicated in purple; cluster two is indicated in orange; and cluster three is

604 indicated in blue. For these results, admixture was allowed, allele frequencies were correlated, and sampling

605 locations were used as a prior. Figure produced using Clumpak (Kopelman et al. 2015) 
Figure 2
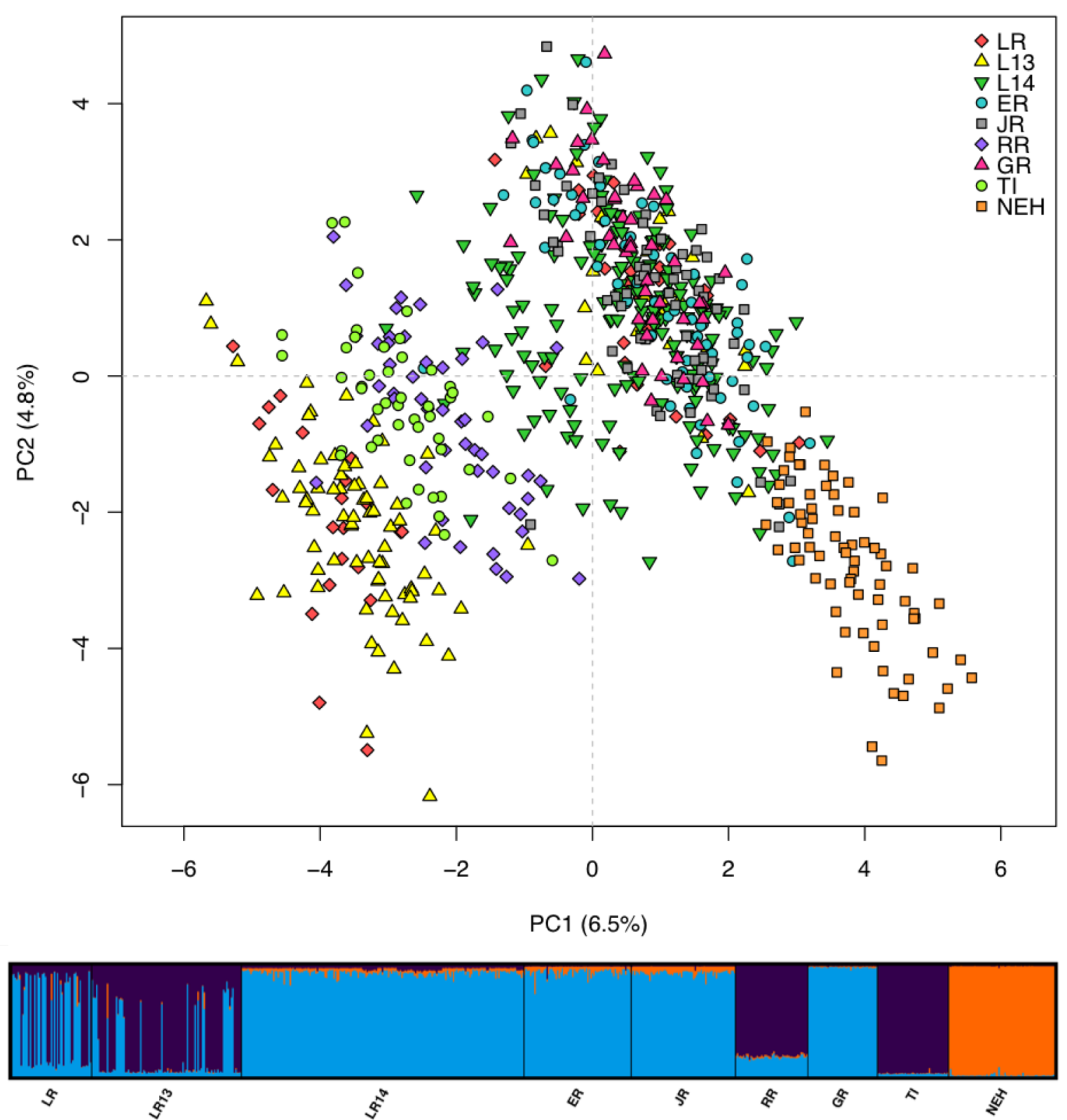


\section{Turley et al. Interannual oyster recruitment}

606 Fig. 3 (a) Results from GENELAND analysis for Crassostrea virginica sampled from the Lafayette River, VA.

607 Colored contours represent probability of belonging to downriver cluster (west toward the mouth) or to the upriver

608 cluster (east toward the head). Adult samples are represented by red diamonds, spat from 2013 are represented by

609 yellow upward pointing triangles, and spat from 2014 are represented by green downward pointing triangles. The

610 size of the symbol for LR13 and LR14 are proportional to the number of samples genotyped from each location. The

611 colorbar on the right is the posterior probability of individuals being assigned to the first cluster. (b) GENELAND

612 results displaying proportion of membership for Lafayette adults, 2013 spat, and 2014 spat to the downriver and

613 upriver clusters 
Figure 3
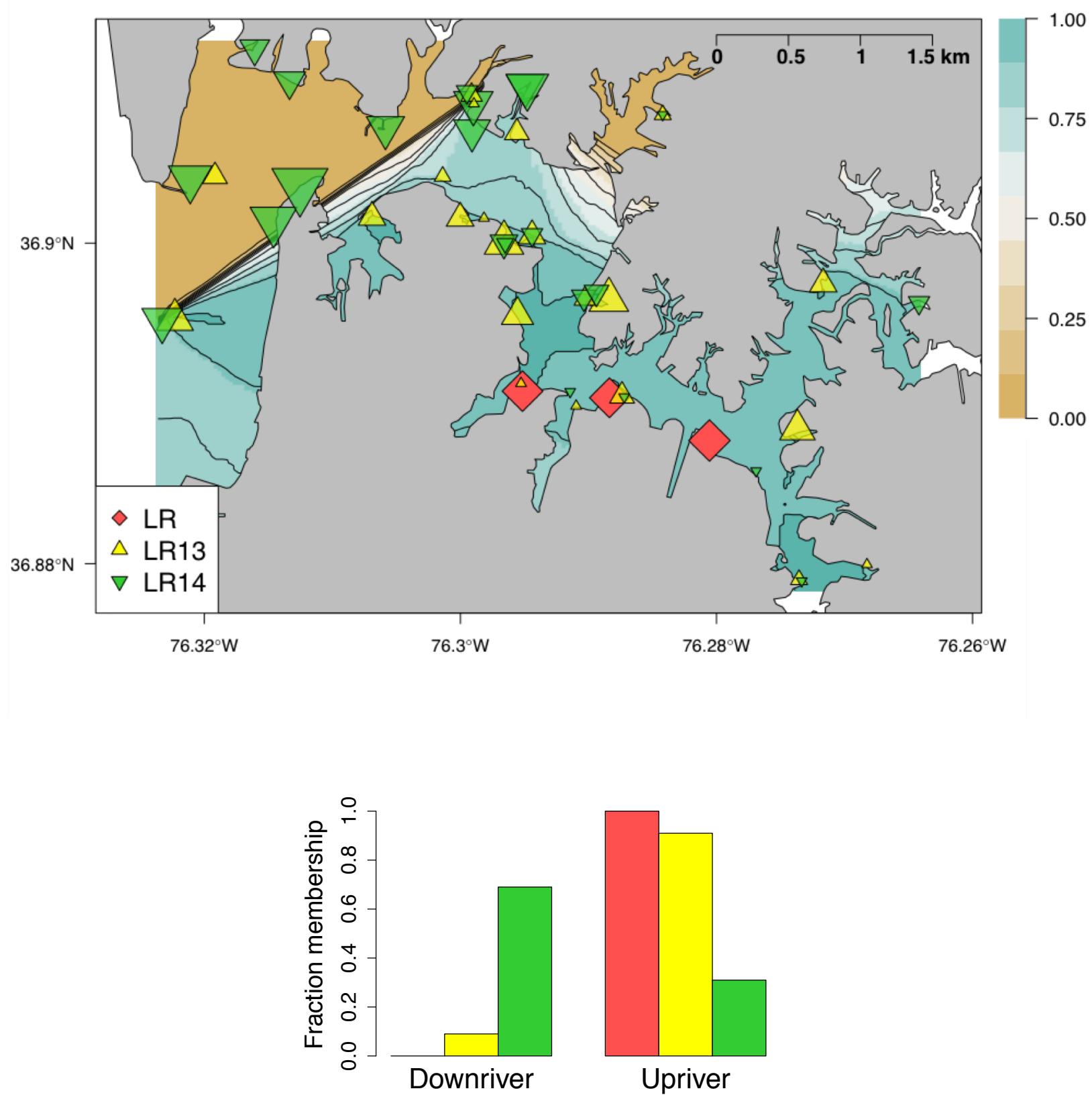

$\square$ LR $\square$ LR13 $\square$ LR14 


\section{Turley et al. Interannual oyster recruitment}

614 Fig. 4 Top row plots display the number of spat per shell from shell-string surveys in 2013 (left column) and 2014

615 (right column). The error bars indicate standard error. Gray symbols near the top of the plots indicate the timing of

616 harmful algal bloom events where circles were events reported in the Lafayette River, the X was an event reported

617 in the Elizabeth River, and triangles were events reported in the James River. The bottom row plots show U winds,

618 which were weekly averaged zonal winds where positive were winds blowing to the east and negative were to the

619 west, and $\mathrm{V}$ winds, which were weekly averaged meridional winds where positive were winds blowing to the north

620 and negative were to the south. Data were observed winds at Norfolk Naval Air Station, VA (Network ID:

621 GHCND:USW00013750, obtained from NOAA National Climatic Data Center) 
Figure 4
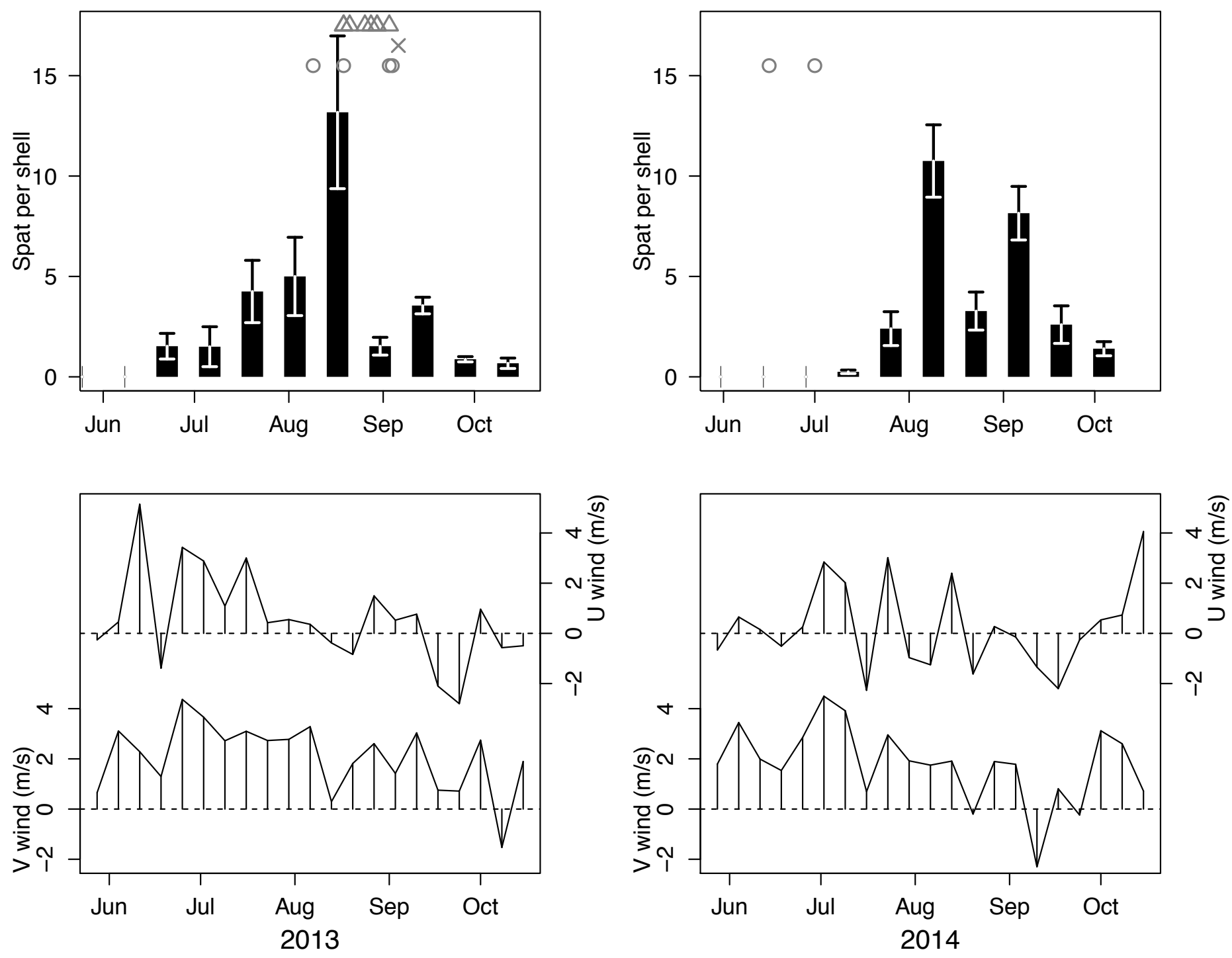
Turley et al. Interannual oyster recruitment

622 Fig. 5 (a) Total spat in 2013 from spat collectors deployed in the Lafayette River by citizen scientists. Monthly 623 averaged wind vectors for July and August are from Norfolk Naval Airbase. Size of symbol is proportional to 624 number of spat recovered at each station. Restoration Reef locations for deployment of experimental oysters are 625 denoted $\mathrm{L}$ for Larchmont ( $\mathrm{NEH}^{\circledR}$ plantings) and $\mathrm{G}$ for Granby (Tangier plantings). In addition, the location of

626 Tanner's Reef is labeled with a T. (b) Total spat in 2013 from spat collectors deployed in the Lafayette River by

627 citizen scientists. Observed monthly averaged wind vectors for July and August are from Norfolk Naval Air Station, 628 VA (Network ID: GHCND:USW00013750, obtained from NOAA National Climatic Data Center) 
Figure 5
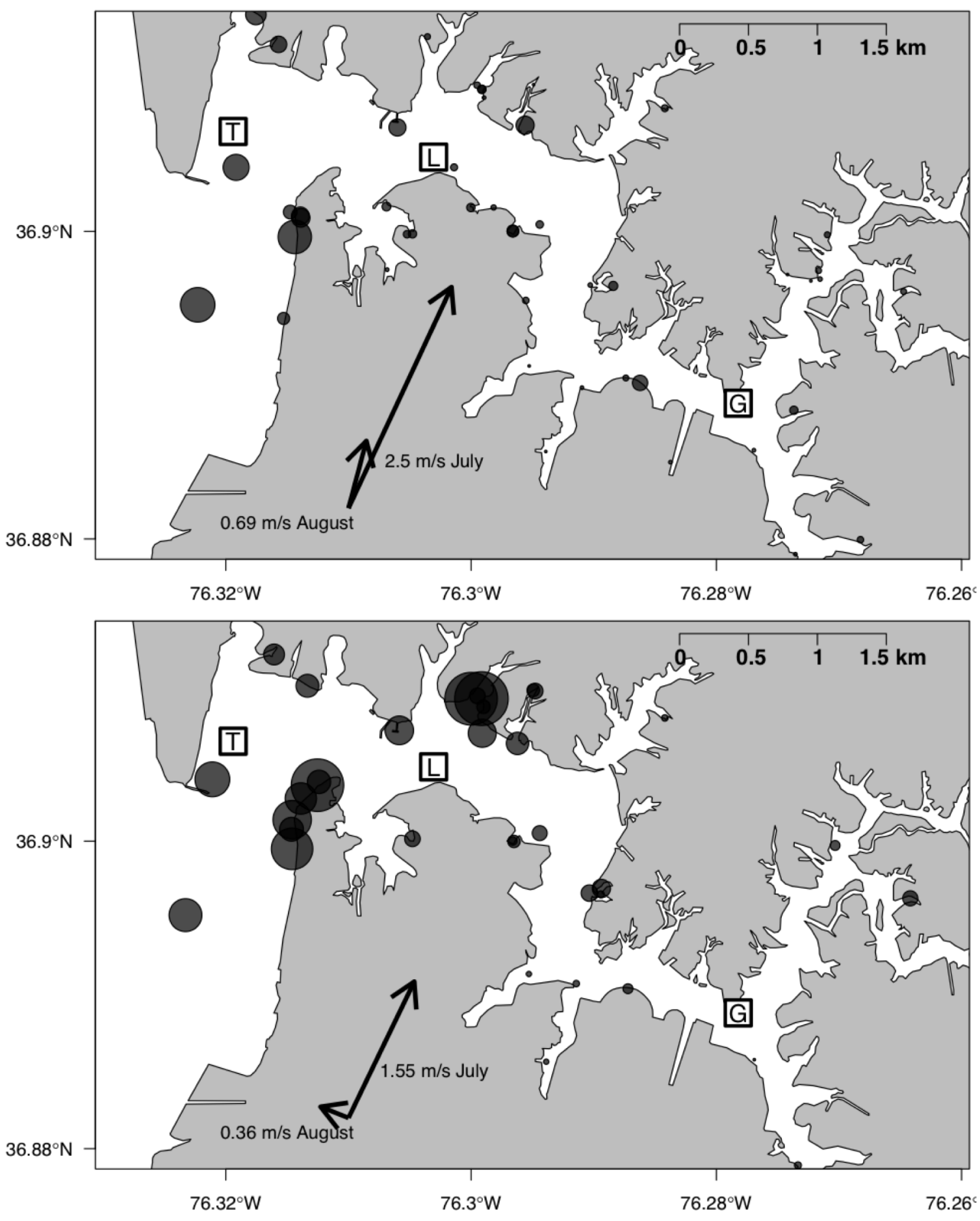
Turley et al. Interannual oyster recruitment

629

630

631 heterozygosity $(\mathrm{He})$, inbreeding coefficient $\left(\mathrm{F}_{\mathrm{IS}}\right)$, and minor allele frequencies (MAF) were calculated over all loci

632 per sample. Median, maximum, minimum and standard deviation (sd) across all loci per sample are displayed. The

633 number of individuals (n) per sample are included

TABLES

Table 1 HWE summary statistics for all samples. Statistics for observed heterozygosity (Ho), expected

\begin{tabular}{|c|c|c|c|c|c|}
\hline Sample & & Ho & $\mathrm{He}$ & $\mathrm{F}_{\text {IS }}$ & MAF \\
\hline \multirow[t]{5}{*}{ LR } & median & 0.32 & 0.32 & 0.02 & 0.20 \\
\hline & $\max$ & 0.60 & 0.51 & 1.00 & 0.50 \\
\hline & $\min$ & 0.29 & 0.31 & 0.07 & 0.22 \\
\hline & sd & 0.17 & 0.17 & 0.24 & 0.15 \\
\hline & $\mathrm{n}=53$ & & & & \\
\hline \multirow[t]{5}{*}{ LR13 } & median & 0.28 & 0.34 & 0.00 & 0.22 \\
\hline & $\max$ & 0.74 & 0.50 & 1.00 & 0.49 \\
\hline & $\min$ & 0.00 & 0.01 & -0.58 & 0.01 \\
\hline & sd & 0.20 & 0.16 & 0.33 & 0.15 \\
\hline & $\mathrm{n}=99$ & & & & \\
\hline \multirow[t]{5}{*}{ LR14 } & median & 0.29 & 0.32 & 0.00 & 0.20 \\
\hline & $\max$ & 0.52 & 0.50 & 1.00 & 0.50 \\
\hline & $\min$ & 0.00 & 0.00 & -0.14 & 0.00 \\
\hline & $\mathrm{sd}$ & 0.17 & 0.18 & 0.26 & 0.16 \\
\hline & $\mathrm{n}=187$ & & & & \\
\hline \multirow[t]{5}{*}{ ER } & median & 0.27 & 0.35 & 0.10 & 0.23 \\
\hline & $\max$ & 0.52 & 0.50 & 0.80 & 0.49 \\
\hline & $\min$ & 0.00 & 0.00 & -0.15 & 0.00 \\
\hline & sd & 0.17 & 0.18 & 0.24 & 0.17 \\
\hline & $\mathrm{n}=71$ & & & & \\
\hline \multirow[t]{5}{*}{ JR } & median & 0.30 & 0.38 & 0.00 & 0.25 \\
\hline & $\max$ & 0.62 & 0.50 & 0.67 & 0.49 \\
\hline & $\min$ & 0.00 & 0.00 & -0.23 & 0.00 \\
\hline & sd & 0.19 & 0.19 & 0.23 & 0.17 \\
\hline & $\mathrm{n}=69$ & & & & \\
\hline \multirow[t]{5}{*}{ RR } & median & 0.32 & 0.37 & -0.04 & 0.24 \\
\hline & $\max$ & 1.00 & 0.51 & 0.54 & 0.50 \\
\hline & $\min$ & 0.00 & 0.00 & -1.00 & 0.00 \\
\hline & $\mathrm{sd}$ & 0.25 & 0.17 & 0.32 & 0.17 \\
\hline & $\mathrm{n}=48$ & & & & \\
\hline \multirow[t]{5}{*}{ GR } & median & 0.28 & 0.33 & 0.02 & 0.21 \\
\hline & $\max$ & 0.57 & 0.50 & 0.56 & 0.50 \\
\hline & $\min$ & 0.00 & 0.00 & -0.15 & 0.00 \\
\hline & sd & 0.17 & 0.18 & 0.19 & 0.15 \\
\hline & $\mathrm{n}=46$ & & & & \\
\hline \multirow[t]{5}{*}{ TI } & median & 0.33 & 0.34 & -0.02 & 0.22 \\
\hline & $\max$ & 1.00 & 0.51 & 0.66 & 0.50 \\
\hline & $\min$ & 0.00 & 0.00 & -1.00 & 0.00 \\
\hline & sd & 0.25 & 0.18 & 0.34 & 0.16 \\
\hline & $\mathrm{n}=47$ & & & & \\
\hline \multirow[t]{4}{*}{$\mathrm{NEH}^{\circledR}$} & median & 0.13 & 0.18 & -0.02 & 0.10 \\
\hline & $\max$ & 0.64 & 0.50 & 0.84 & 0.49 \\
\hline & $\min$ & 0.00 & 0.00 & -0.30 & 0.00 \\
\hline & sd & 0.22 & 0.21 & 0.28 & 0.18 \\
\hline
\end{tabular}


Turley et al. Interannual oyster recruitment

634

$\mathrm{n}=70$

$\mid$

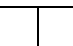

|

$+\mid$ 
Turley et al. Interannual oyster recruitment

635 Table 2 Pairwise $F_{S T}$ values for oyster samples. The upper half of the matrix are p-values where bold underlined

636 values are significant $(\mathrm{p}<0.01$, Benjamini-Yekutieli corrected $\mathrm{p}$-value). The lower half of the matrix are the

637 pairwise $\mathrm{F}_{\mathrm{ST}}$ values with significant values bolded and underlined

\begin{tabular}{|c|c|c|c|c|c|c|c|c|c|}
\hline & LR & LR13 & LR14 & ER & JR & RR & GR & TI & $\mathrm{NEH}^{\circledR}$ \\
\hline LR & & $\underline{0.01}$ & $\underline{0.00}$ & $\underline{\mathbf{0 . 0 0}}$ & $\underline{\mathbf{0 . 0 0}}$ & $\underline{\mathbf{0 . 0 0}}$ & $\underline{0.00}$ & 1.00 & $\underline{0.00}$ \\
\hline LR13 & $\underline{0.01}$ & & $\begin{array}{l}\underline{0.00} \\
\end{array}$ & $\underline{\underline{0.00}}$ & $\underline{\underline{0.00}}$ & $\underline{\underline{0.00}}$ & $\underline{0.00}$ & 1.00 & $\underline{0.00}$ \\
\hline LR14 & $\underline{0.01}$ & $\underline{0.03}$ & & 0.40 & 0.55 & $\underline{0.00}$ & $\underline{0.00}$ & 1.00 & $\underline{0.00}$ \\
\hline ER & $\underline{0.01}$ & $\underline{0.03}$ & 0.00 & & 0.96 & $\underline{\mathbf{0 . 0 0}}$ & $\underline{0.01}$ & 0.34 & $\underline{0.00}$ \\
\hline JR & $\underline{0.01}$ & $\underline{0.03}$ & 0.00 & 0.00 & & $\underline{0.00}$ & $\underline{0.00}$ & 0.32 & $\underline{0.00}$ \\
\hline RR & $\underline{0.02}$ & $\underline{0.01}$ & $\underline{\mathbf{0 . 0 3}}$ & $\underline{0.04}$ & $\underline{0.04}$ & & $\underline{0.00}$ & 1.00 & $\underline{0.00}$ \\
\hline GR & $\underline{0.02}$ & $\underline{0.04}$ & $\underline{0.01}$ & $\underline{0.01}$ & $\underline{0.01}$ & $\underline{0.05}$ & & 0.71 & $\underline{0.00}$ \\
\hline TI & -0.02 & -0.03 & -0.01 & 0.00 & 0.00 & -0.04 & 0.00 & & $\underline{0.00}$ \\
\hline $\mathrm{NEH}^{\circledR}$ & $\underline{0.12}$ & $\underline{0.12}$ & $\underline{0.10}$ & $\underline{\mathbf{0 . 1 0}}$ & $\underline{0.10}$ & $\underline{0.14}$ & $\underline{0.13}$ & $\underline{0.14}$ & \\
\hline
\end{tabular}


Turley et al. Interannual oyster recruitment

639 Table 3 Oysters planted by the Chesapeake Bay Foundation into the Lafayette River

\begin{tabular}{|l|l|l|r|l|}
\hline Year & Location, Lafayette River & Origin & Number & Method \\
\hline 2011 & Larchmont Reef & Rappahannock & 397,012 & spat on shell \\
\hline 2012 & Tanner's Point & Rappahannock & 727,145 & spat on shell \\
\hline 2013 & Granby Reef & Tangier Island & $1,800,000$ & spat on shell \\
\hline 2013 & Larchmont Reef & NEH $^{\circledR}$ & 114,000 & cultchless \\
\hline
\end{tabular}




\section{Turley et al. Interannual oyster recruitment}

641 Electronic Supplementary Material 1: Details concerning the SNP panel development, significance testing

642 correction, and connectivity model. In addition, supplementary figures are included. Figure S1 are results from

643 relatedness analysis. Figure S2 are results from shell-string survey. Figure S3 are depictions of the connectivity

644 model output. Supplementary table 1 displays across sample Hardy-Weinberg statistics results, table S2 are linkage

645 analysis results, and table S3 are ANOVA results of shell-string data.

646

647 Electronic Supplementary Material 2: Table listing the single nucleotide polymorphism markers used for this study

648 including marker names, putative gene, base pair alternates, literature reference, Genebank accession number, and

649 primer sequences used for methods. 